\title{
Impact of congenital calcitonin deficiency due to dysgenetic hypothyroidism on bone mineral density
}

M. Daripa, F.J.A. Paula, A.C.B. Rufino and M.C. Foss
Divisão de Endocrinologia, Departamento de Clínica Médica, Faculdade de Medicina de Ribeirão Preto, Universidade de São Paulo, Ribeirão Preto, SP, Brasil

\section{Correspondence \\ F.J.A. Paula \\ Departamento de Clínica Médica FMRP, USP \\ Av. Bandeirantes, 3900 \\ 14049-900 Ribeirão Preto, SP \\ Brasil \\ E-mail: fjpaula@fmrp.usp.br \\ Research supported by CNPq \\ and FAEPA.}

Publication supported by FAPESP.

Received July 15, 2003

Accepted November 11, 2003

\begin{abstract}
The objective of the present study was to determine the effect of chronic calcitonin deficiency on bone mass development. The results of 11 patients with thyroid dysgenesis (TD) were compared to those of 17 normal individuals (C) and of 9 patients with other forms of hypothyroidism $(\mathrm{OH}): 4$ with hypothyroidism due to inborn errors of thyroid hormone synthesis and 5 with Hashimoto's thyroiditis. The subjects received an intravenous calcium stimulus and blood was collected for the determination of ionized calcium $\left(\mathrm{Ca}^{2+}\right)$, calcitonin, and intact parathyroid hormone. Bone mineral density (BMD) was determined by dual-energy X-ray absorptiometry. After calcium administration the levels of $\mathrm{Ca}^{2+}$ in the two groups of hypothyroidism were significantly higher than in the normal control group (10 $\mathrm{min}$ after starting calcium infusion: $\mathrm{C}=1.29 \pm 0.08 v s \mathrm{TD}=1.34 \pm 0.03 v s$ $\mathrm{OH}=1.34 \pm 0.02 \mathrm{mmol} / \mathrm{l} ; \mathrm{P}<0.05)$, and only the TD group showed no calcitonin response ( $5 \mathrm{~min}$ after starting calcium infusion: $\mathrm{C}=27.9 \pm$ $5.8 v s \mathrm{TD}=6.6 \pm 0.3 v s \mathrm{OH}=43.0 \pm 13.4 \mathrm{ng} / \mathrm{l})$. BMD values did not differ significantly between groups (L2-L4: $\mathrm{C}=1.116 \pm 0.02 v s \mathrm{TD}=$ $1.109 \pm 0.03 v s \mathrm{OH}=1.050 \pm 0.04 \mathrm{~g} / \mathrm{cm}^{2}$ ). These results indicate that early deficiency of calcitonin secretion has no detrimental effect on bone mass development. Furthermore, the increased calcitonin secretion observed in patients with inborn errors of thyroid hormone biosynthesis does not confer any advantage in terms of BMD.
\end{abstract}

Key words - Osteoporosis

- Hypothyroidism

- Calcitonin

- Bone mineral density .....................

\section{Introduction}

Osteoporosis is a systemic disease characterized by a decreased amount of bone mass and microarchitectural degeneration of bone tissue which increases the susceptibility to fracture. Bone mass, a major determi- nant of the risk of osteoporotic fracture, increases during childhood and adolescence, reaching its peak in the third decade of life (1). Several lines of evidence suggest that genetic factors are responsible for almost $80 \%$ of variation in peak bone mass (2). However, nutritional and environmental fac- 
tors, hormonal disorders, and other diseases can significantly affect bone mass gain during the acquisition period $(1,3)$. The bone mass of an adult corresponds to the bone mass reached at the peak of the bone-forming period minus the loss that occurs subsequently. Therefore, for a better understanding of the mechanisms involved in the development of osteoporosis the study of the factors associated with bone loss rate in adults is as important as the evaluation of the impact of several factors related to the increase in bone mass during the period of bone mass anabolism.

Calcitonin is a potential calciotropic hormone that has an inhibitory effect on osteoclast activity in vitro (4) and can also stimulate urinary loss of calcium and phosphate (5). However, the clinical significance of calcitonin deficiency has been difficult to demonstrate (6). The physiological role of calcitonin in the maintenance of bone mass is suggested by studies showing that conditions associated with osteoporosis such as age (7) and female sex $(8,9)$ show lower serum calcitonin levels than observed in young individuals and in males. Furthermore, calcitonin administration increases bone mineral density (BMD) in postmenopausal women $(10,11)$. In contrast, several studies have shown that acquired calcitonin deficiency or excess has no effect on bone mass or mineral metabolism in adults (12) and the only long-lasting randomized study of calcitonin treatment showed that the effect of calcitonin on bone mass gain was less than expected (13).

There are few data about the impact of congenital calcitonin deficiency on bone mass $(14,15)$ and, as far as we know, there is no study evaluating bone mass by double-energy X-ray absorptiometry (DEXA) in these patients. Therefore, the objective of the present study was to determine the BMD of individuals with congenital nongoitrous hypothyroidism (thyroid agenesis and sublingual thyroid) and to compare them with the
BMD values of controls and for individuals with congenital hypothyroidism due to a defect in hormone synthesis and with acquired hypothyroidism due to Hashimoto's thyroiditis. We also determined calcitonin secretion and parathyroid hormone (PTH) suppression during intravenous calcium infusion in these patients.

\section{Subjects and Methods}

The study was conducted on 37 subjects, 17 controls (10 females and 7 males - group C), 11 with thyroid dysgenesis ( 7 females and 4 males - group TD), and 9 with other forms of hypothyroidism (5 with Hashimoto's thyroiditis and 4 with disorder of thyroid hormonal synthesis, 7 females and 2 males group $\mathrm{OH}$ ). There was no significant difference in physical characteristics between groups (Table 1). Among patients with congenital hypothyroidism, only 6 had precociously started hormone replacement therapy. Two patients with sublingual thyroid had started therapy at 9 and 13 years of age, respectively. The other patients did not provide reliable information concerning the onset of hormone therapy.

The study was approved by the Ethics Committee of the University Hospital, School of Medicine of Ribeirão Preto, USP, and all subjects and/or responsible family members gave written informed consent to participate in the study.

The three groups were defined on the basis of clinical and laboratory evaluation. Normal individuals had no personal or family history of metabolic and bone disease and the subjects with thyroid disease had no other disorder in addition to that under evaluation. The etiological diagnosis of dysgenetic hypothyroidism was made by $\left[{ }^{131} \mathrm{I}\right]$-thyroid scintigraphy in 9 patients (4 with thyroid agenesis and 5 with sublingual thyroid). $\left[{ }^{131} \mathrm{I}\right]-$ scanning was not performed in two patients because they were already under treatment when referred to the University Hospital. 
Individuals with a history of tobacco smoking, alcoholism, use of drugs with known effects on mineral metabolism (estrogen, barbiturics, vitamin $\mathrm{D}$, diuretics, corticosteroids) were excluded from the study. The patients with TD had significantly higher thyroid-stimulating hormone (TSH) values than the other groups (TSH: $\mathrm{C}=1.8 \pm 0.5 v s$ $\mathrm{TD}=13.7 \pm 7.8 v s \mathrm{OH}=5.9 \pm 2.6 \mathrm{mU} / \mathrm{l})$ but there was no significant difference in serum thyroxine $\left(\mathrm{T}_{4}\right)$ or prolactin (PRL) levels between groups (Table 1). The levels of testosterone, estradiol, S-dehydroxyepiandrostenedione (S-DHEA), $\Delta-4$ androstenedione, calcium, alkaline phosphatase, and cortisol were normal and did not differ significantly between groups. The patients with hypothyroidism were using a physiological dose of L-thyroxine (1-2.2 $\mu \mathrm{g} / \mathrm{kg}$ body weight). All subjects were submitted to BMD evaluation in the lumbar spine (L2-L4), and femoral neck. BMD was assessed by DEXA (Sophos, LXRA, Paris, France) and the results are reported as $\mathrm{g} / \mathrm{cm}^{2}$ and $\mathrm{Z}$ score.

Eight individuals of the groups with hypothyroidism agreed to participate in the calcium infusion test. The experiments were performed in the morning beginning between 7:00 and 9:00 am, in a metabolic study room at a constant temperature of $22^{\circ} \mathrm{C}$. The volunteers were in the postabsorptive state (10$12 \mathrm{~h}$ of fast) and stayed in the supine position during the experiment. Cubital veins were cannulated in each forearm with 20-gauge catheters for blood collection and solution infusion, respectively. After $30 \mathrm{~min}$ of rest to allow equilibration of plasma albumin and calcium levels, the first basal sample was collected for testosterone, estradiol, SDHEA, $\Delta-4$ androstenedione, calcium, alkaline phosphatase, $\mathrm{T}_{4}, \mathrm{TSH}, \mathrm{PRL}$, ionized calcium, calcitonin, and intact PTH (iPTH) determinations. Two other basal blood samples were drawn at 10-min intervals for ionized blood calcium and serum calcitonin and iPTH measurements, and the infusion of calcium gluconate was then started. Two milligrams of elemental calcium per $\mathrm{kg}$ body weight diluted in 5\% glucose for a total volume of $50 \mathrm{ml}$ was infused at a constant rate with an infusion pump (Harvard Apparatus; Millis, MA, USA) for $5 \mathrm{~min}$. Thereafter, sampling times were at the end of infusion (5 min) and at 10 and $20 \mathrm{~min}$ for ionized blood calcium and serum iPTH and calcitonin determinations.

Samples for ionized blood calcium were collected anaerobically with a syringe containing calcium-titrated heparin ( $\mathrm{PICO}^{\mathrm{TM}} 70$, Radiometer, Copenhagen, Denmark) and determinations were performed immediately after collection using an analyzer with a calcium-specific electrode (Radiometer ICA II, Copenhagen, Denmark). Serum samples for iPTH and calcitonin measurements were separated in a refrigerated centrifuge and frozen at $-70^{\circ} \mathrm{C}$ until the day for the determinations. iPTH was determined by an immunoradiometric method (Nichols Diagnostic Institutes, San Juan Capistrano, CA, USA). The intra- and interassay coefficients of variation were 5.1 and $10 \%$, respectively. Radioimmunoassay was used for calcitonin determination (Nichols Diagnostic Institutes) and intra- and interassay coefficients of variation were 5.2 and $11.7 \%$, respectively. Luteinizing hormone ( $\mathrm{LH})$, follicle-stimulating hormone (FSH), estradiol, PRL, and S-DHEA were determined by radioimmunoassay and free $\mathrm{T}_{4}$ and TSH were determined by immunochemiluminescence (Immulite, Diagnostic Products Corporation, Los Angeles, CA, USA).

\section{Statistical analysis}

Data are reported as means \pm SEM. Data were analyzed using the Graphpad Prism 1999 software (Graphpad Software Inc., San Diego, CA, USA). The two-way Friedman test for analysis of variance by ranks was used for paired parameters and the KruskalWallis test was used for unpaired variables. Dunn's post-test was used in both analyses. 
Table 1. Clinical data of controls and patients with thyroid dysgenesis (TD) and of patients with hypothyroidism due to disorders of hormonal synthesis and Hashimoto's thyroiditis $(\mathrm{OH})$.

\begin{tabular}{lccc}
\hline & \multicolumn{1}{c}{ Controls } & TD & $\mathrm{OH}$ \\
\hline $\mathrm{N}$ (gender) & $17(10 \mathrm{~F}, 7 \mathrm{M})$ & $11(7 \mathrm{~F}, 4 \mathrm{M})$ & $9(7 \mathrm{~F}, 2 \mathrm{M})$ \\
Age (years) & $32 \pm 2(21-47)$ & $30 \pm 3(18-45)$ & $34 \pm 2(26-44)$ \\
Weight $(\mathrm{kg})$ & $64 \pm 3(47-83)$ & $65 \pm 3(46-80)$ & $63 \pm 4(51-86)$ \\
Height $(\mathrm{cm})$ & $163 \pm 0.02(148-188)$ & $159 \pm 0.03(141-179)$ & $157 \pm 0.03(145-173)$ \\
$\mathrm{BMI}\left(\mathrm{kg} / \mathrm{m}^{2}\right)$ & $23.9 \pm 0.1(20.1-28.2)$ & $25.6 \pm 1.2(20.3-33.7)$ & $25.3 \pm 1.1(21.8-29.8)$ \\
$\mathrm{T}_{4}(\mathrm{nmol} / \mathrm{l})$ & $108 \pm 6(69-135)$ & $104 \pm 10(54-141)$ & $101 \pm 13(57-142)$ \\
$\mathrm{TSH}(\mathrm{mU} / \mathrm{l})$ & $2.2 \pm 0.4(0.7-5.0)$ & $8.7 \pm 3.8(0.2-33.0)$ & $6.2 \pm 2.0(0.2-19.5)$ \\
$\mathrm{PRL}(\mu \mathrm{g} / \mathrm{l})$ & $16.9 \pm 0.4(6.2-34.2)$ & $16.1 \pm 2.0(8.0-25.4)$ & $14.8 \pm 2.7(6.2-13.6)$ \\
\hline
\end{tabular}

$\mathrm{BMI}=$ body mass index; $\mathrm{T}_{4}=$ thyroxine; $\mathrm{TSH}=$ thyroid-stimulating hormone; $\mathrm{PRL}=$ prolactin.

Figure 1. Circulatory levels of $A$, ionized calcium $(\mathrm{mmol} / \mathrm{l}), B$, calcitonin (ng/l), and $C$, intact parathyroid hormone (iPTH, ng/l) obtained under basal conditions and after intravenous calcium administration for controls (C), for patients with thyroid dysgenesis (TD), and for patients with hypothyroidism due to disorders of hormonal synthesis and Hashimoto's thyroiditis $(\mathrm{OH})$. Data are reported as means \pm SEM for 8 patients in each group. ${ }^{*} \mathrm{P}<0.05$ for $\mathrm{C}$ vs TD, ${ }^{*} \mathrm{P}<0.05$ for $\mathrm{C}$ vs $\mathrm{OH},+\mathrm{P}<$ 0.05 for $\mathrm{TD}$ vs $\mathrm{OH}$, and ${ }^{++} \mathrm{P}<$ 0.01 for TD vs OH (two-way Friedman test for paired variables and Kruskal-Wallis test for unpaired variables).


The level of significance was set at $\mathrm{P}<0.05$.

\section{Results}

The serum levels of calcium, inorganic phosphorus, magnesium, cortisol, LH, FSH, and estradiol were normal and there was no significant difference between groups. Table 1 shows serum levels of $\mathrm{T}_{4}, \mathrm{TSH}$ and PRL for the three groups. The patients with TD showed higher TSH levels, which were above normal in four patients.

Basal ionized calcium was similar in the three groups. However, after calcium administration the circulatory levels reached in the two groups with hypothyroidism were significantly higher than in controls $(10 \mathrm{~min}$ after starting calcium infusion: $\mathrm{C}=1.29 \pm$ $0.08 v s \mathrm{TD}=1.34 \pm 0.03$ vs $\mathrm{OH}=1.34 \pm 0.02$ $\mathrm{mmol} / \mathrm{l}, \mathrm{P}<0.05$; Figure 1).

Patients with TD presented basal calcitonin levels similar to control but significantly lower than those for the other group with hypothyroidism $(\mathrm{C}=11.0 \pm 1.8$ vs $\mathrm{TD}=6.0$ $\pm 0.5 v s \mathrm{OH}=16.0 \pm 3.5 \mathrm{ng} / \mathrm{l}, \mathrm{P}<0.01)$. After the calcium stimulus, the patients with TD maintained similar values, while controls and patients with Hashimoto's disease and disturbed hormonal synthesis presented a significant elevation in calcitonin levels (5 min after starting calcium infusion: $\mathrm{C}=27.9$ $\pm 5.8 v s \mathrm{TD}=6.6 \pm 0.3 v s \mathrm{OH}=43.0 \pm 13.4$ $\mathrm{ng} / \mathrm{l}, \mathrm{P}<0.01)$. The patients with disturbed hormonal synthesis were responsible for the higher basal and stimulated calcitonin levels of $\mathrm{OH}$ individuals, since patients with Hashimoto's disease presented serum calcitonin levels similar to controls.

The $\mathrm{OH}$ group tended to have higher basal serum iPTH levels than the other groups $(\mathrm{C}=26.5 \pm 8.0$ vs $\mathrm{TD}=25.5 \pm 3.9$ vs $\mathrm{OH}=$ $46.3 \pm 6.2 \mathrm{ng} / \mathrm{l})$, a pattern that was maintained over all intervals after calcium administration $(+5: \mathrm{C}=11.9 \pm 2.7$ vs $\mathrm{TD}=10.3 \pm$ $3.0 v s \mathrm{OH}=17.6 \pm 4.8 \mathrm{ng} / \mathrm{l}$ ) but, again, there were no significant difference between groups (Figure 1) 
The three groups did not show significant differences in BMD values at the sites evaluated. When the values were expressed as $\mathrm{g} / \mathrm{cm}^{2}$ the values obtained for the various groups were as follows: L2-L4, C $=1.116 \pm$ $0.02 v s \mathrm{TD}=1.109 \pm 0.03 v s \mathrm{OH}=1.050 \pm$ $0.04 \mathrm{~g} / \mathrm{cm}^{2}$, and femoral neck, $\mathrm{C}=0.909 \pm$ 0.03 vs $\mathrm{TD}=0.910 \pm 0.03$ vs $\mathrm{OH}=0.892 \pm$ $0.05 \mathrm{~g} / \mathrm{cm}^{2}$ (Figure 2). These results, expressed as Z score, were: $\mathrm{L} 2-\mathrm{L} 4, \mathrm{C}=0.113 \pm$ $0.17 v s \mathrm{TD}=0.03 \pm 0.26 v s \mathrm{OH}=-0.33 \pm$ $0.41 \mathrm{SDM}$, and femoral neck, $\mathrm{C}=0.00 \pm$ 0.26 vs $\mathrm{TD}=-0.103 \pm 0.32$ vs $\mathrm{OH}=-0.08 \pm$ $0.50 \mathrm{SDM}$. Analysis of the results obtained for females showed similar BMD in the three groups (L2-L4: $\mathrm{C}=1.113 \pm 0.03$ vs $\mathrm{TD}=$ $1.109 \pm 0.03$ vs $\mathrm{OH}=1.077 \pm 0.05 \mathrm{~g} / \mathrm{cm}^{2}$ and femoral neck: $\mathrm{C}=0.863 \pm 0.03$ vs $\mathrm{TD}=$ $\left.0.866 \pm 0.04 v s \mathrm{OH}=0.905 \pm 0.06 \mathrm{~g} / \mathrm{cm}^{2}\right)$.

\section{Discussion}

The present data suggest that congenital calcitonin deficiency is not a condition that prevents the development of normal bone mass in human beings. Indeed our results showed that young and middle-aged adults with hypothyroidism and chronic calcitonin deficiency have normal BMD. Additionally, our results showed that patients with congenital hypothyroidism due to disorders of hormonal synthesis have higher calcitonin secretion which, however, does not confer any advantage in terms of bone mass development.

Probably the only similarity between thyroid follicular cells and $\mathrm{C}$ cells is to share the final localization in the same organ. However, these cells differ in their origin and especially in terms of their known physiological role. Disorders of follicular cells influence the economy of the organism as a whole, including bone, whereas the ablation or hyperactivity of $\mathrm{C}$ cells apparently has no clinical consequence (16). C cells are derived from the neural crest and migrate to the thyroid during embryogenesis. The bioavail-

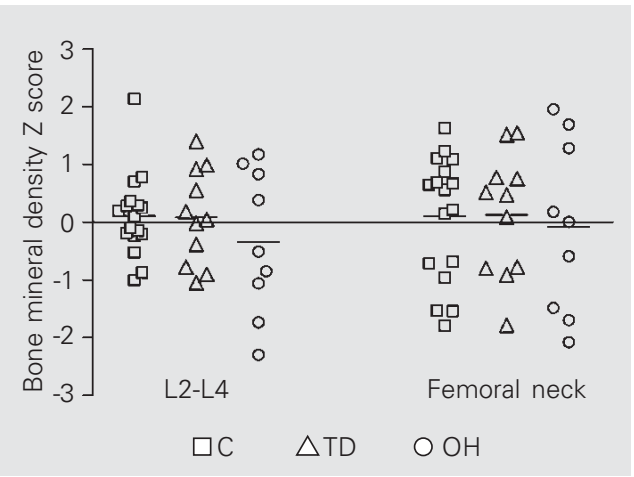

ability of C cells in patients with TD is not known; however, in this condition their survival or activity may be impaired. Our results confirm previous studies showing that patients with nongoitrous hypothyroidism have a reduced or absent basal calcitonin response to different stimuli. Detectable calcitonin levels in these patients can be ascribed to extrathyroid production or to detection of nonmonomeric calcitonin by immunoassay (17). There is no apparent explanation for the reduction of calcitonin secretion in patients with lingual thyroid.

However, Demeester-Mirkine et al. (15) hypothesized that adequate $\mathrm{C}$ cell development might require the presence of factors secreted by follicular cells, and that cells that have not migrated adequately do not have a normal function. Interestingly, in support of this hypothesis, our data show that patients with dysgenetic hypothyroidism have decreased calcitonin secretion while congenital goitrous patients have increased calcitonin secretion. Previous studies also demonstrated increased calcitonin values in patients with other causes of thyroid disorders (18-20). Our patients had no clinical, ultrasonographic or cytopathological evidence of medullary thyroid carcinoma. Hypercalcitoninemia can also result from low levels of 1,25-dihydroxyvitamin D3 [1,25- $\left.(\mathrm{OH})_{2} \mathrm{D} 3\right]$. Lazaretti-Castro et al. (21) and Zabel and Dietel (22) showed that $1,25-(\mathrm{OH})_{2}$ D3 downregulates thyroid $\mathrm{C}$ cells and it is well known that the principal cells of the parathyroid gland are also down-regulated by $1,25-(\mathrm{OH})_{2}$
Figure 2. Bone mineral density $Z$ scores for L2-L4 and femoral neck of controls (C), of patients with thyroid dysgenesis (TD), and of patients with hypothyroidism due to disorders of hormonal synthesis and Hashimoto's thyroiditis $(\mathrm{OH})$. 
D3 (23). We observed that the patients with a higher calcitonin response were also those with higher basal serum iPTH. Unfortunately, we did not determine circulatory $1,25-(\mathrm{OH})_{2}$ D3 levels and cannot attribute the alterations in PTH and calcitonin levels to a possible deficit of 1,25- $(\mathrm{OH})_{2} \mathrm{D} 3$.

The groups of patients with hypothyroidism presented greater elevation of ionized blood calcium than controls after calcium administration. Previously, Anast and Guthrie (24) described similar decreased calcium tolerance in treated patients with TD. The authors attributed the pattern of the calcium curve to the deficiency of calcitonin. However, this hypothesis cannot be applied to all patients with hypothyroidism. We verified the same behavior of the calcium curve in both groups of hypothyroidism independently of calcitonin deficiency. Thus, our results may suggest alteration in the set point of the calcium sensor, since a greater elevation of ionized calcium was not associated with a greater suppression of PTH secretion after calcium administration to these patients. Poloyan et al. (25) detected the occurrence of parathyroid hyperplasia in chronic hypothyroidism, and it is well known that parathyroid hyperplasia is associated with decreased sensitivity in the set point of the calcium sensor (26).

Body et al. (27) evaluated serum calcitonin levels in children with congenital nongoitrous hypothyroidism from birth to adolescence and observed that the fall in calcitonin levels was particularly marked in early infancy, suggesting that the impairment in calcitonin secretion is an early occurrence in these patients. Therefore, if calcitonin has an important role in bone mass acquisition we may speculate that adults with congenital calcitonin deficiency would have osteopenia. This hypothesis was not confirmed by our results. The normal BMD values in L2L4 and in the femoral neck observed in our patients indicate that individuals with chronic calcitonin deficiency are not at a disadvan- tage in terms of reaching normal BMD. Our results are consistent with studies on adults which have demonstrated that acquired calcitonin deficiency or excess has no effect on bone mineral content. Contrary to our results, Kruse et al. (14) and Demeester-Mirkine et al. (15) detected decreased radial BMD in patients with nongoitrous hypothyroidism. However, the results obtained in our study are not comparable since Kruse et al. (14) studied individuals with a mean age of 16.8 years and Demeester-Mirkine et al. (15) also included 15-year-old patients in their study. Additionally, in the cited studies BMD was assessed by single-photon absorptiometry, whereas we used DEXA which is currently considered to be the gold standard method for BMD evaluation.

Recently, Hoff et al. (28) obtained surprising results concerning bone mass development in an experimental model using knockout mice for the calcitonin gene. These animals developed a greater volume of trabecular bone than the control group, probably due to their greater bone formation rate. These results were a milestone in the study of the physiological role of calcitonin and permitted the authors to propose the unexpected hypothesis that calcitonin may have a modulatory effect on osteoblasts by inhibiting their activity. Although the artificial conditions present in the animal model used by Hoff et al. (28) are not directly comparable to the model of chronic calcitonin deficiency used in our study, the present data at least support the idea that calcitonin deficiency does not seem to be a limiting factor of bone mass development.

The effect of hypothyroidism on BMD has not been well established. It has been reported that hypothyroidism is associated with higher (29) or normal BMD (30). However, there are no data showing the effect of late treatment on BMD in children with congenital hypothyroidism. Thyroid hormone is essential for normal growth and maturation of the skeleton. Since severe hypothyroid- 
ism usually leads to impaired growth and pubertal development we would expect reduced bone mass acquisition. Unfortunately, BMD assessment was not available for our patients when they were in a condition of clinical and biochemical hypothyroidism.

The present results suggest that calcitonin is not an important hormone for bone mass development in human beings. Patients with TD, a condition associated with early reduction of calcitonin secretion, present BMD similar to controls and to patients with other forms of hypothyroidism. The deficit of calcitonin secretion verified in this study probably reflects chronic calcitonin deficiency in patients with dysgenetic hypothy- roidism. Nevertheless, the BMD in L2-L4 and in the femoral neck was normal in these patients. Two decades before, Body and Heath (9) stated that calcitonin is a hormone in search of a function. Today, after the biochemical and molecular characterization as well as the therapeutic use of calcitonin, the physiological importance of this hormone has not yet been clearly established.

\section{Acknowledgments}

The authors gratefully acknowledge Sebastião L. Brandão Filho and Nadia Bittar for skillful technical assistance.

\section{References}

1. Peacock M, Turner $\mathrm{CH}$, Econs MJ \& Foroud F (2002). Genetics of osteoporosis. Endocrine Reviews, 23: 303-326.

2. Heaney RP, Abrams S, Dawson-Hughes B, Looker A, Marcus R, Matkovic V \& Weaver C (2000). Peak bone mass. Osteoporosis International, 11: 985-1009.

3. Seeman E (2002). Pathogenesis of bone fragility in women and men. Lancet, 359: 1841-1850.

4. Chambers TJ, Chambers JC, Symonds J \& Darby JA (1986). The effect of human calcitonin on the cytoplasmic spreading of rat osteoclasts. Journal of Clinical Endocrinology and Metabolism, 63: 1080-1085.

5. Neradilova M, Blahosova A \& Reisenauer R (1977). Acute effect of large dose of calcitonin on calcium, magnesium and inorganic phosphate levels in rat serum in correlation to differences in thyroid function. Physiologia Bohemoslovaca, 26: 331-336.

6. McDermott MT \& Kidd GS (1987). The role of calcitonin in the development and treatment of osteoporosis. Endocrine Reviews, 8: 377-390.

7. Heath III H \& Sizemore GW (1977) Calcitonin in normal man: differences between men and women. Journal of Clinical Investigation, 60: $1135-1140$.

8. Body JJ (1993). Calcitonin: from the determination of circulating levels in various physiological and pathological conditions to the demonstration of lymphocyte receptors. Hormone Research, 39: 166-170.

9. Body JJ \& Heath III H (1983). Estimates of circulating monomeric calcitonin: Physiological studies in normal and thyroidectomized men. Journal of Clinical Endocrinology and Metabolism, 57: 897903.

10. Reginster J-Y, Denis $D$, Albert A, Deroisy R, Lecart MP, Fontaine MA, Lambelin P \& Franchimont P (1987). One-year controlled randomized trial of prevention of early postmenopausal bone loss by intranasal calcitonin. Lancet, 2: 1481-1483.

11. Mclntyre I, Stevenson JC, Whitehead MI, Wimalawansa SJ, Banks
LM \& Healy MJ (1988). Calcitonin for prevention of postmenopausal bone loss. Lancet, 1: 900-902.

12. Hurley DL, Tiegs RD, Wahner HW \& Heath III H (1987). Axial and appendicular bone mineral density in patients with long-term deficiency or excess of calcitonin. New England Journal of Medicine, 317: 537-541.

13. Chesnut III CH, Silverman S, Andriano K et al. (2000). A randomized trial of nasal spray salmon calcitonin in postmenopausal women with established osteoporosis: the PROOF study. American Journal of Medicine, 109: 267-276.

14. Kruse K, Süss A, Büsse M \& Schneider $P$ (1987). Monomeric serum calcitonin and bone turnover during anticonvulsivant treatment and in congenital hypothyroidism. Journal of Pediatrics, 111: 57-63.

15. Demeester-Mirkine N, Bergmann P, Body JJ \& Corvilair J (1990). Calcitonin and bone mass status in congenital hypothyroidism. Calcified Tissue International, 46: 222-226.

16. Austin LA \& Heath III H (1981). Calcitonin physiology and pathophysiology. New England Journal of Medicine, 34: 269-278.

17. Weissel M, Kainz H, Tyl E, Ogunyemi E \& Woloszczuk W (1991). Clinical evaluation of new assays for determination of serum calcitonin concentrations. Acta Endocrinologica, 124: 540-544.

18. Libbey NP, Nowakowski KJ \& Tucci JR (1989). C-cell hyperplasia of the thyroid in a patient with goitrous hypothyroidism and Hashimoto's thyroiditis. American Journal of Surgery and Pathology, 13: 987-989.

19. Vierhapper H, Nowotny P, Bielglmayer CL \& Gessl A (2002). Prevalence of hypergastrinemia in patients with hyper and hypothyroidism: impact for calcitonin. Hormone Research, 57: 85-89.

20. Barbott N, Guyetant S, Beldent V, Akrass A, Cerf I, Perdrisot R \& Bigorgne JC (1991). Chronic autoimmune thyroiditis and C-cell hyperplasia. Study of calcitonin secretion in 24 patients. Annales d'Endocrinologie, 52: 109-112.

21. Lazaretti-Castro M, Grauer A, Raue F \& Ziegler R (1990). 1,25Dihydroxyvitamin D3 suppresses dexamethasone effects on calci- 
tonin secretion. Molecular and Cellular Endocrinology, 71: R13-R18.

22. Zabel M \& Dietel M (1991). Calcitriol decreases calcitonin secretion from a human medullary carcinoma cell line via specific receptor action. Acta Endocrinologica, 125: 229-234.

23. Naveh-Many T, Raue F, Grauer A \& Silver J (1992). Regulation of calcitonin gene expression by hypocalcemia, hypercalcemia, and vitamin D in the rat. Journal of Bone and Mineral Research, 7: 12331237.

24. Anast CS \& Guthrie RA (1971). Decreased calcium tolerance in nongoitrous cretins. Pediatric Research, 5: 668-672.

25. Poloyan WR, Kazuko E, Gopalsami L, Bassali J, Lawrence AM \& Poloyan E (1997). Hyperparathyroidism associated with chronic hypothyroidism state. Laryngoscope, 107: 903-909.

26. Indridason OS \& Quarles LD (1999). Tertiary hyperparathyroidism and refractory secondary hyperparathyroidism. In: Favus MJ (Editor), Primer on the Metabolic Bone Disease and Disorders of Min- eral Metabolism. Lippincott Williams \& Wilkins, Philadelphia, PA, USA, 198-202.

27. Body JJ, Chanoine JP, Dumon JC \& Delange F (1993). Circulating calcitonin levels in healthy children and subjects with congenital hypothyroidism from birth to adolescence. Journal of Clinical Endocrinology and Metabolism, 77: 565-567.

28. Hoff AO, Lehnen-Catala P, Thomas PM et al. (2002). Increased bone mass is an unexpected phenotype associated with deletion of the calcitonin gene. Journal of Clinical Investigation, 110: 1849-1857.

29. Larsen PR \& Davies TF (2002). Hypothyroidism and thyroiditis. In: Larsen PR, Kronenberg HM, Melmed S \& Polonsky KS (Editor), Williams Textbook of Endocrinology. Saunders, Philadelphia, PA USA, 423-456.

30. Wiersinga WM (2001). Hypothyroidism and myxedema coma. In: DeGroot LJ \& Jameson JL (Editor), Endocrinology. Vol. 2. W.B. Saunders, Philadelphia, PA, USA, 1491-1506. 